\title{
Post Operative Pain
}

\author{
Jorge Paredes Vieyra*, Fabian Ocampo Acosta and Francisco Javier Jiménez Enriquez \\ Universidad Autonoma De Baja California, Mexico
}

Submission:September 28, 2017; Published: November 27, 2017

*Corresponding author: Jorge Paredes Vieyra, Universidad Autonoma De Baja California, Tijuana, Mexico, Email: jorgitoparedesvieyra@hotmail.com

Abstract

Aim: To compare incidence of post-operative pain and apical healing after single-visit or two-visit root canal treatment of teeth with necrotic pulp and apical periodontitis after a two-year control period.

Methodology: All teeth of the one and two-visit group were asymptomatic (92) and symptomatic (18) with a diagnosis of pulp necrosis (RCT cases) determined by hot and cold sensitivity tests and radiographically all teeth showed a small and irregular radiolucency at the tooth apex. Working length was established with EAL and confirmed radiographically. Reciprocating files (VDW, Munich Germany) were used to complete root canal preparation. EDTA served as a lubricant.

Results: Randomization allocated 50 teeth to single-visit and 60 teeth to two-visit treatment. Four teeth in the single-visit and 9 in the twovisits group were lost to follow-up leaving a total of 97 teeth that were evaluated at the 2-year follow-up period (46 single-visit, 51 two-visits; (Figure 1) (Table $1 \& 2$ )). The occurrence of Post-operative pain and flare-up was positively associated only with the treatment of previously symptomatic teeth with periradicular lesions $(\mathrm{p}=0.05)$. Moderate pain occurred in $2 \%$ of the one-visit group and $1.6 \%$ of the two-visit group of the previously asymptomatic/symptomatic teeth, the treatment was effective in eliminating pain in $77.5 \%$, and in $66.66 \%$, respectively, of the retreatment cases (Table $2 \& 3$ ). At the end of the study, 44 of the 46 teeth (95.65\%) in the single-visit group and 48 (94.11\%) of the 51 teeth in the two-visit group were classified as healed (Table 2). The number of cases classified as uncertain was 1 in the single-visit group (2.17\%) as compared with 2 in the two-visit group (3.92\%). The number of cases classified as not healed was $1(2.17 \%)$ in the single-visit group as compared with $1(1.96 \%)$ in the two-visit group. The statistical analysis of the healing results did not show any significant difference between the groups $(\mathrm{p}=0.05)$.

Conclusion: This study gave evidence that a meticulously instrumentation and irrigation performed in a single-visit root canal treatment can be as successful as a two visits treatment. There was a minor incidence of flare-ups in teeth that needed retreatment than in primary treatment. Post-operative pain is defined as pain of any degree that occurs after initiation of root canal treatment [1]. Post-endodontic pain, particularly after initial endodontic therapy should ideally be eliminated by the therapy; however, analgesics are frequently required to diminish pain. There is a strong relationship between pulp status, microorganisms and postoperative pain, influencing the experience of pain, which may undermine the patient's confidence in the procedure and the clinician [2]. This event is an undesirable occurrence for both patients and clinicians.

\section{Introduction}

Certain factors may predispose to the development of postoperative pain, such as preoperative pain and retreatment. Although microorganisms are regarded as the primary cause of post-operative pain, inevitable extrusion of the irrigant solution, or debris that contain necrotic tissue, microorganisms, pulpal fragments and dentine particles from the root canal space into the periradicular tissues may also lead to post-operative pain $[1,2]$.

Dentinal debris, pulp tissue, microorganisms, and irrigants can be conveyed to the periradicular tissues during root canal preparation, and such extrusion of debris can lead to postoperative complications, such as flare-ups. This is a condition occurring within a few hours to a few days after a root canal treatment especially in teeth with necrotic pulp $[1,2]$.

Acute pain of endodontic origin describes what is referred as hyperalgesia. Hyperalgesia is characterized by pain of a spontaneous nature, a reduced pain threshold, and an increase in the perceived magnitude of painful stimuli [1]. The AAE [3] described flare-up as an acute exacerbation of an asymptomatic pulpal and or periradicular pathosis after the initiation or continuation of root canal treatment. Some etiological factors have been suggested to play a role in flare-up including preoperative pain, pulp vitality and microbial infection, inadequate debridement and extrusion of debris and filling material into the periradicular area. Studies have reported a 
widely varying incidence of flare-ups ranging from $1.4 \%$ to $16 \%$ $[4,5]$.

Post-operative pain after an endodontic procedure is usually associated to the presence of periapical inflammation, which may be the result of over-instrumentation, over-filling, and passage of medicine or infected debris into the periapical tissues, damage of the vital neural or pulpal tissues or central sensitization [6]. The issue remains controversial since opinions vary greatly as to the relative risks and benefits of single-visit versus multiple-visits root canal treatment of teeth with necrotic pulp and apical periodontitis.

Periradicular periodontitis is an inflammatory disease comprising host response to infection of the root canal system of the affected tooth [7]. Most of endodontic problems are microbial in origin, removal of microorganisms is considered the most important step in root canal therapy $[8,9]$. Reduction of the microbial load as well as the disruption of biofilms are achieved by a combination of mechanical instrumentation, irrigation with tissue dissolving and microbicide solutions, and application of antimicrobial medicaments in the root canal between appointments [10].

Many studies reported significant reduction of bacteria with an increase in preparation size and irrigation [10,11]. On the other hand, Peters \& Wesselink [12] demonstrated that more than $30 \%$ of the root canal walls remained untouched even by modern rotary NiTi instrumentation techniques. The reciprocating motion involves an initial rotation of the instrument in a counterclockwise direction, during which the instrument penetrates and cuts the dentin, and then a rotation in the opposite direction, during which the instrument is released.

Mechanical debridement combined with antibacterial irrigation using $0.5 \%$ sodium hypochlorite can render $40-60 \%$ of the treated teeth bacteria negative $[13,14]$. In addition to mechanical debridement and antibacterial irrigation, dressing the canal with calcium hydroxide has been shown to increase the percentage of bacteria negative teeth to around 70\% [11]. Single-visit root canal treatment has become common practice and offers some advantages such as a reduced flare-up rate $[15,16]$, reduced number of appointments and reduced cost.

It is understood that single-visit treatments are based on the clinical opinion that additional appointments would not improve the quality of care [17]. However, even though an inter appointment dressing with calcium hydroxide decreases the bacterial count it does not assure total eradication of intra canal microbes [10]. The purpose of this randomized controlled trial was to clinically and radiographic compare the incidence of post-operative pain following one-versus two-visit root canal treatment of teeth with necrotic pulp and apical periodontitis after a 2-year healing period. We hypothesized that necrotic teeth with apical periodontitis treated in two appointments with calcium hydroxide, as an intra canal medication would show superior healing at 2 years when compared with teeth treated in one appointment.

\section{Materials and Methods}

The institutional review board of the Facultad de Odontología Tijuana México approved the study protocol and all the participants were treated in accordance with the Helsinki Declaration [18]. The study started in November 2014 and ended in December 2016. The main inclusion criteria were:

a. Radiographic evidence of apical periodontitis
(minimum size $\geq 2.0 \mathrm{~mm} \times 2.0 \mathrm{~mm}$ )

b. A diagnosis of pulpal necrosis confirmed by negative response to hot and cold tests. The author performed thermal pulp testing, and one certified oral surgeon verified radiographic interpretation.

\section{Patient selection}

One hundred and ten of one hundred and twenty patients (63 women and 47 men), 18 to 60 years of age (mean=55years) with 110 eligible teeth consented to participate in the study. The study design is shown in Figure 1. Patient selection was based on the following criteria:

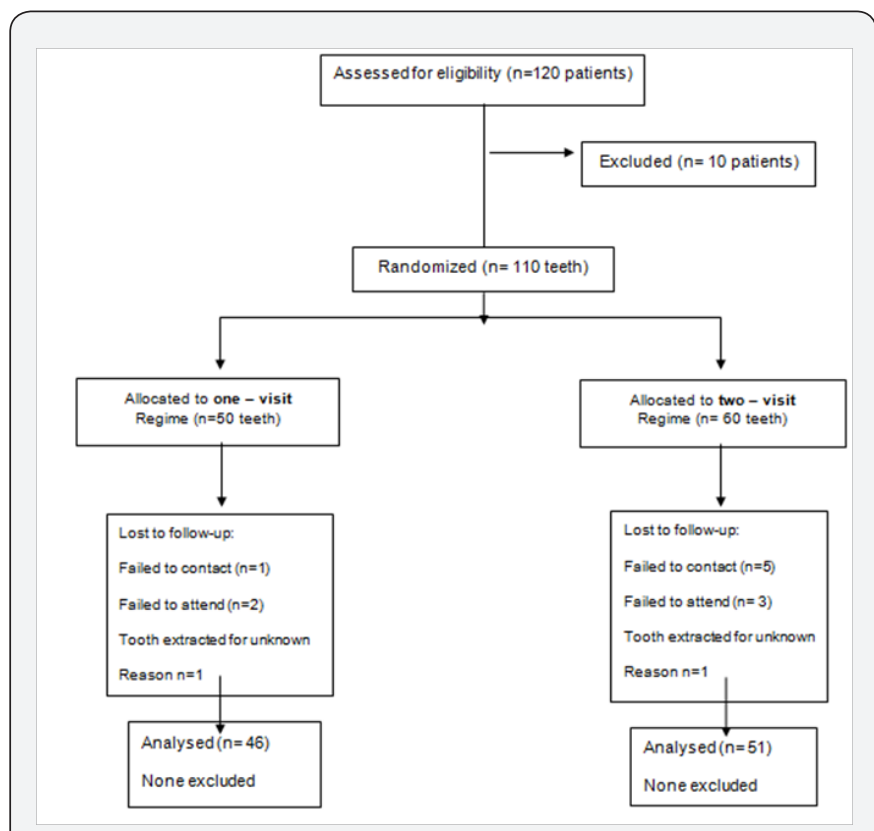

Figure 1: Flow diagram of the progress of phases of the trial.

A. The aims and requirements of the study were freely accepted.

B. Treatment was limited to patients in good health.

C. All teeth had nonvital pulps and apical periodontitis, with or without a sinus tract.

D. A negative response to hot and cold pulp sensitivity tests. 
E. Presence of sufficient coronal tooth structure for rubber dam isolation.

F. No prior endodontic treatment on the involved tooth.

G. No analgesics or antibiotics were used five days before the clinical procedures began.

Exclusion criteria included the following:

A. Patients who did not meet inclusion requirements.

B. Patients who did not provide authorization for participation.

C. Patients who were younger than 16years old.

D. Patients who were pregnant.

E. Patients who were diabetic.

F. Patients with a positive history of antibiotic use within the past month.

G. Patients whose tooth had been previously accessed or endodontically treated.

H. Teeth with root resorption.

I. Immature/open apex, or a root canal in which patency of the apical foramen could not be established were all excluded from the study. Teeth with periodontal pockets deeper than $4 \mathrm{~mm}$ also were excluded of the study.

Once eligibility was confirmed, the study was explained to the patient by the authors, and the patient was invited to participate. After explaining the clinical procedures and risks and clarifying all questions raised, each patient signed a written informed consent form and was randomly assigned to either the onevisit or the two-visit group by using a block of random numbers generated by one of the investigators.

Randomization was performed before the clinical examination using the minimization method described by Pocock [19]. Three randomization factors were considered: tooth group, size of periapical lesion and pre-and post-operative pain as a clinical symptom (Table $1 \& 3$ ). A medical history was obtained and a clinical examination performed. All teeth of the one and twovisit group were 92 asymptomatic and 18 symptomatic with a diagnosis of pulp necrosis determined by hot and cold sensitivity tests and radiographically all teeth showed a small and irregular radiolucency at the tooth apex (Schick Technologies, Long Island City, NY, USA). The diagnostic findings were checked by comparing the tooth's response against that of an adjacent tooth with a vital pulp. Periodontal probing revealed no increased probing depth $(>3 \mathrm{~mm})$ around any of the teeth. The author performed all the clinical procedures.

Table 1: Distribution of teeth by randomization factors.

\begin{tabular}{|c|c|c|c|c|}
\hline \multirow{2}{*}{ Tooth Group } & One-Visit & One-Visit & Two-Visit & Two-Visit \\
\cline { 2 - 5 } & Treatment & Follow Up & Treatment & Follow Up \\
\cline { 2 - 5 } & $(\mathbf{n}=\mathbf{5 0}(\mathbf{\%})$ & $\mathbf{( n = 4 6 ) ( \% )}$ & (n=60) (\%) & (n=51) (\%) \\
\hline Incisors and canines & $20(40 \%)$ & $19(41.30 \%)$ & $23(38.33 \%)$ & $18(35.29)$ \\
\hline Bicuspids & $13(26 \%)$ & $12(26.08 \%)$ & $21(35 \%)$ & $11(21.57 \%)$ \\
\hline Molars & $17(34 \%)$ & $15(32.60 \%)$ & $16(26.67 \%)$ & $21(41.17 \%)$ \\
\hline$<2 \mathrm{~mm}$ & $11(22 \%)$ & $11(23.91 \%)$ & $31(51.67)$ & $19(37.25 \%)$ \\
\hline $2-5 \mathrm{~mm}$ & $24(48 \%)$ & $21(45.65 \%)$ & $20(33.33 \%)$ & $11(21.56 \%)$ \\
\hline$>5 \mathrm{~mm}$ & $15(30 \%)$ & $14(30.43 \%)$ & $9(15 \%)$ & \\
\hline
\end{tabular}

Table 2: Distribution of teeth according to outcome classification in the two experimental groups.

\begin{tabular}{|c|c|c|c|c|}
\hline Radiographic Condition & $\mathbf{n}$ & One-Visit & Two-Visit & Total \\
\hline & 97 & $(n=46)(\%)$ & $(n=51)(\%)$ & $(\%)$ \\
\hline Healed & & $44(95.65 \%)$ & $48(94.11 \%)$ & $92(94.84 \%)$ \\
\hline Uncertain healing & & $1(2.17 \%)$ & $2(3.92 \%)$ & $3(3.09 \%)$ \\
\hline Not healed & & $1(2.17 \%)$ & $1(1.96 \%)$ & $2(2.06 \%)$ \\
\hline \multicolumn{5}{|c|}{$p=0.05$} \\
\hline
\end{tabular}

Healed is defined as success 
Open Access Journal of Neurology \& Neurosurgery

Table 3: Occurrence of postoperative pain and flare up in different clinical conditions.

\begin{tabular}{|c|c|c|c|c|c|c|c|}
\hline \multirow{2}{*}{$\begin{array}{c}\text { Clinical } \\
\text { Condition }\end{array}$} & \multicolumn{2}{|c|}{ Preoperative Pain } & \multirow[t]{2}{*}{ n } & \multicolumn{4}{|c|}{ Postoperative Pain } \\
\hline & Asymptomatic & Symptomatic & & Absent & Mild & Moderate & Flare up \\
\hline \multicolumn{8}{|l|}{ Treatment } \\
\hline One-visit & 32 & 8 & 50 & $47(94 \%)$ & $1(2 \%)$ & $1(2 \%)$ & 0 \\
\hline Two-visit & 60 & 10 & 60 & $56(93.33 \%)$ & $3(5 \%)$ & $1(1.6 \%)$ & $1(1.6 \%)$ \\
\hline Total & 92 & 18 & 110 & $103(93.63 \%)$ & $4(3.63 \%)$ & $2(1.81 \%)$ & $1(.90 \%)$ \\
\hline \multicolumn{8}{|c|}{$\mathrm{p}=0.05$} \\
\hline
\end{tabular}

\section{Treatment protocol}

All treatment sessions were approximately 50minutes in length to allow for acceptable time for completion of treatment in one or two visits. The author performed all the clinical procedures. The standard procedure for both groups at the first visit included local anesthesia with 2\% lidocaine with 1:100,000 epinephrine (Septodont Saint-Maur des Fossés, France) and rubber dam isolation the tooth was disinfected with 5.25\% $\mathrm{NaOCl}$ (Ultra bleach, Bentonville, AR, USA).

Carious dentine was completely removed and endodontic access cavities prepared with sterile high-speed carbide burs \#331 (SS White. Lakewood, NJ, USA) and Zekrya Endo burs (Dentsply-Maillefer, Ballaigues, Switzerland). After gaining access, the canals were explored with \#06, \#08, and \#10 K-type hand files (Flex-R files, Moyco/Union Broach, York PA, USA) according to the initial diameter of the foramen, its degree of flattening, and its canal curvature using a watch-winding motion. Working Length was established by introducing a \#10 K-file up to the apical foramen as determined by a Root ZX (J Morita, Irvine, CA, USA), and then by withdrawing the file and subtracting $0.5 \mathrm{~mm}$ from the length, which was measured with the aid of an endodontic ruler. The WL was confirmed radiographically (Schick Technologies, Long Island City, NY, USA).

The root canals were negotiated and enlarged with hand instruments (Flex-R files, Moyco/Union Broach, York PA, USA) until reaching an ISO size \#20 at working length. The coronal portions of the root canals were flared with sizes 2-3 GatesGlidden burs (Dentsply Maillefer). Irrigation with $2 \mathrm{~mL} 2.5 \%$ sodium hypochlorite $(\mathrm{NaOCl})$ was performed using a 24-G needle (Max-I-Probe; Dentsply Tulsa Dental, York, PA) during access and a 31-G NaviTip needle (Ultradent Products Inc., South Jordan, UT) when reaching the WL after each file insertion. Reciprocating files (VDW, Munich Germany) were used to complete root canal preparation. EDTA (Roth International Ltd, Chicago, IL, USA) served as a lubricant.

All Reciprocating files were driven by an electric micro motor with limited torque (VDW Silver Reciproc Motor, VDW). R25 files (25.08) were used in narrow and curved canals, and R40 files (40.06) were used in large canals. Three in-and-out (pecking) motions were applied with stroke lengths not exceeding $3 \mathrm{~mm}$ in the cervical, middle, and apical thirds until attaining the established WL. All the files were used in only 1 tooth (single use) and then discarded. Patency of the apical foramen was maintained during all the techniques by introducing \#10 K-type file at WL. The preparations for all the groups were finished using a \#45 file for narrow or curved canals and a \#60 file for wide canals.

After completion of instrumentation, all root canals were irrigated with $2.5 \mathrm{~mL} 17 \%$ EDTA acid (Roth International) for 30 seconds followed by a final irrigation with $5.0 \mathrm{~mL} 5.25 \%$ $\mathrm{NaOCl}$ using the EndoVac irrigation system (Discus Dental, Culver City, CA, USA). For the single visit group, the root canals were dried with sterile paper points and obturated at the same appointment using lateral condensation of gutta percha and Sealapex sealer (SybronEndo). Access cavities of anterior teeth were etched and restored with Fuji IX (GC Corp, Tokyo, Japan). For posterior teeth, a buildup restoration was placed using the same etching technique and Fuji IX. For the two-visit group, the root canals were dried and medicated with calcium hydroxide powder (Roth, International) with distilled water in a creamy consistency. The paste was prepared by using equal volumes of $\mathrm{Ca}(\mathrm{OH}) 2$ powder and distilled water, and applied meticulously into the root canal using endodontic hand files.

The access cavities (occlusal/palatal surface) were sealed with Cavit (3M ESPE, Seefeld, Germany) and the quality of the calcium hydroxide powder filling was checked radiographically. Patients of the two-visit group were scheduled for a second appointment to complete root canal therapy at least 1 week after the initial appointment. At the second appointment, the calcium hydroxide paste was removed with hand instruments and copious irrigation with distilled water followed by $2.5 \mathrm{~mL}$ $17 \%$ EDTA and a final rinse with $5.0 \mathrm{~mL} 5.25 \% \mathrm{NaOCl}$ using the EndoVac irrigation system. Following removal of the calcium hydroxide, the root canals were dried with sterile paper points, and obturation was performed with the same technique described for the single-visit group: Post treatment radiographs were taken and all teeth were restored with a Fuji IX buildup.

After completing the endodontic treatment procedure (in both groups), all patients were given postoperative instructions to take analgesics (400mg ibuprofen) in the event of pain at a dosage of 1 tablet every 6 hours. The level of discomfort was rated as follows: no pain; mild pain, which was recognizable but 
not discomforting; moderate pain, which was discomforting but bearable (analgesics, if used, were effective in relieving pain); flare-up, which was difficult to bear (analgesics, if used, were ineffective in relieving pain). Cases with severe postoperative pain and/or the occurrence of swelling were classified as flareups and treated accordingly (Table 3). After completion of RCT, patients were instructed to return to their referring dentist for definitive restoration as soon as possible.

Patients were contacted by telephone by the clinical assistant after 24 hours, 48 hours, 72 hours, and 7 days and asked to provide the following information: their perceived pain rating and whether they had taken the analgesic medication prescribed and, if so, the quantity of tablets and the number of days required to control the pain. All the patients were instructed to contact the clinic or the dentist in charge of their treatment if the analgesic medication failed to provide pain relief or in the event of any other type of emergency.

\section{Two-year follow-up}

The healing results were clinically and radiographically evaluated 2 years postoperatively. All radiographs obtained preoperatively and at follow-up were coded blind and organized in random order. Two pre-calibrated endodontists (author not included) independently evaluated all radiographs under moderate illumination at a light table using a $2 \mathrm{x}$-magnifying viewer equipped with a masking frame of the same size as the dental film. Before evaluation of the study images, each examiner graded a series of 10 radiographic images not associated with the study sample and representing a wide range of periapical bone densities.

To minimize false-positive diagnoses, observers used a strict definition of periapical disease $[19,20]$. In case of disagreement, joint re-evaluation was performed until a consensus was reached on all images. All radiographs were obtained by using the same digital imaging system (Schick Technologies). The periapical index (PAI) scale described by Ørstavik [21] was used as a scoring system to evaluate radiographic healing [19] as shown in Table 4.

The primary outcome measure for this study was classified by using a modification of Strindberg's criteria [22] used for assessment of radiographic healing. Teeth with symptoms of persisting periapical inflammation were scored as not healed, as were the cases with periapical radiolucency's that remained unchanged or increased in size (Table 2). Teeth with a reduced periapical rarefaction were judged as uncertain. Teeth with complete restitution of the periodontal contours were judged as healed. In teeth with more than one root, the least favorable outcome was recorded.

Secondary outcome measures were the presence of clinical symptoms or abnormal findings at the end or during a two-year observation period (spontaneous pain, presence of sinus tract, swelling, mobility, periodontal probing depths greater than baseline measurements, or sensitivity to percussion or palpation) as shown in Table 3. The overall incidence of postoperative discomfort was recorded and expressed as a percentage of the total number of teeth evaluated. The associations between the variables as well as the flare-up rates in both groups were compared. Incidence of postoperative pain was also calculated for each studied variable. SPSS software (Statistical Package for Social Sciences, v.21.0; IBM Corp, Chicago, IL) was used for the statistical treatment of results. The Kruskal-Wallis nonparametric test was applied to compare the incidence of postoperative pain. The level of significance adopted was 5\% (P $<.05)$.

\section{Result}

The baseline demographic and clinical features of the study groups are summarized in Table 1 . Ten patients were excluded of the study because they were younger than 18 years old (3 patients), pregnant ( 2 patient), had a positive history of antibiotic use within the past month (5 patients). One of the 10 excluded teeth had periodontal pocket deeper than $4 \mathrm{~mm}$ also were excluded of the study. Randomization allocated 50 teeth to single-visit and 60 teeth to two-visit treatment. Four teeth in the single-visit and 9 in the two-visits group were lost to followup leaving a total of 97 teeth that were evaluated at the 2-year follow-up period (46 single-visit, 51 two-visits; (Figure 1) (Table $1 \& 2))$.

\section{Incidence of post-operative pain and flare-ups}

The occurrence of Post-operative pain and flare-up was positively associated only with the treatment of previously symptomatic teeth with periradicular lesions $(\mathrm{p}=0.05)$. Moderate pain occurred in $2 \%$ of the one-visit group and $1.6 \%$ of the twovisit group. Of the previously Asymptomatic/symptomatic teeth, the treatment was effective in eliminating pain in $77.5 \%$ of the cases (Table $2 \& 3$ ).

Some level of postoperative pain occurred in $2 \%$ of the onevisit group and $5 \%$ of the two-visit group. Postoperative pain was significantly associated with previously symptomatic teeth and apical periodontitis. $(\mathrm{p}=0.05)$. No other correlations were detected between the occurrence of a flare-up and postoperative discomfort and other clinical conditions. Flare-up occurred in $1.6 \%$ of the two-visit group. Data are summarized in Table 2-4.

\section{Post-operative pain and apical healing}

At the end of the study, 44 of the 46 teeth (95.65\%) in the single-visit group and $48(94.11 \%)$ of the 51 teeth in the twovisit group were classified as healed (Table 2). The number of cases classified as uncertain was 1 in the single-visit group $(2.17 \%)$ as compared with 2 in the two-visit group (3.92\%). The number of cases classified as not healed was $1(2.17 \%)$ in the single-visit group as compared with $1(1.96 \%)$ in the two-visit group. 
One patient (single-visit group) presented with persistent draining sinus tracts at 24 months (presented with sinus tracts at the initial treatment appointment) as shown on Table 1. The statistical analysis of the healing results did not show any significant difference between the groups $(p=0.05)$.

\section{Discussion}

The purpose of this randomized study was to compare Incidence of post-operative pain and apical healing after singlevisit or two-visit RCT of teeth with necrotic pulp and apical periodontitis after a two-year control period. One of the major obstacles to assessing postoperative pain encountered in clinical studies conducted for this purpose is the subjective nature of this evaluation and the inherent difficulty in measuring pain. The incidence of postoperative pain and particularly of flareups was positively associated with the treatment of previously symptomatic teeth with periradicular lesions. Studies have shown that the presence of preoperative pain can significantly increase the probability of postoperative pain $[1,2,5]$. There are conflicting results about the influence of periradicular bone destruction on the incidence of postoperative pain. Our results agree with those from a recent study [23], which found that root canal treatments with postoperative pain occurring shortly after treatment could result in long-term success whereas treatment without such pain may result in failure. Two other studies $[10,24]$ reported that discomfort was the most common shortterm outcome of root canal treatment procedures.

Table 4: The PAI was used to evaluate radiographic healing.

\begin{tabular}{|c|c|}
\hline Pai Score & Description of Radiographic Findings \\
\hline 1 & Normal periapical structures \\
\hline 2 & Small changes in bone structures (PAI $\leq 2)$ \\
\hline 3 & Changes in bone structures (PAI $\geq 3$ ) \\
\hline & \\
\hline 4 & Periodontitis with well defined radiolucent area \\
\hline 5 & Severe periodontitis \\
\hline
\end{tabular}

Several factors are involved in the sensation of postoperative pain. This makes clinical investigations that associate pain incidence with possible causes even more challenging, unfortunately, the measurement of discomfort is fraught with hazards and opportunities for errors. It is necessary to rate the level of discomfort in categories arranged in advance and exactly described by authors [25]. Yoldas [25] suggested accurate criteria to categorize patient's pain. The results of this study were like those reported by previous studies [26,27] where no significant differences in the occurrence of flare-ups were observed, when comparing single-visit vs. two-visit root canal treatment. DiRenzo [27] found a significantly higher incidence of flare-ups in teeth that needed retreatment and were treated in one-visit than those with multiple-visit root canal treatment (Table 4). In our study, two patients (2.5\%) experienced a flare- up in teeth that had received primary root canal treatment (Table 3). Flare-up occurred in $4.5 \%$ of the cases.

We found that previously symptomatic teeth with radiolucent areas were more susceptible to flare-ups. Our results agree with the study by Torabinejad [28]. A higher incidence of postoperative pain in teeth without periradicular lesions might be attributed to a lack of space for pressure release when periradicular bone resorption is absent [29]. Some studies have reported a significantly higher incidence of flare-ups in teeth that needed retreatment

A. However, we found no correlation between the incidence of postoperative pain in cases of treatment or retreatment. In contrast, Walton and Fouad

B. Found no significant difference in flare-up incidence between treatment and retreatment cases.

Most studies on single visit endodontics have focused on post-operative pain and flare-up [29,30], even though pain has been shown to have no effect on long-term healing success [31,32]. Historically, several treatments strategies and interappointment dressings were used for infected teeth but over the years, the number of sessions has been reduced [33]. A twovisit model using an inter-appointment dressing with calcium hydroxide has been proposed as a standard [33]. Several factors play an important role in the decision-making process between single-visit versus two-visit endodontics and the endodontic competence of clinicians becomes the overriding factor in determining the outcome of any treatment.

The probability that teeth treated in two visits with an inter appointment dressing of calcium hydroxide would result in improved healing when compared with one-visit root canal therapy was not supported by the results of the present study. We did not attempt to balance the number of multi-rooted teeth in each group, although multi-rooted teeth with apical periodontitis have a lower possibility of complete healing when compared with single-rooted teeth [34]. A determination of healed, not healed, or uncertain was made radiographically 2 years following treatment. However, since radiographic images of periapical bone lesions range from impossible or difficult to see to being easily seen false-positives were minimized in this study because periapical radiolucency's were recorded only when certain. Our results agree with Peters \& Wesselink [35], Weiger [36], Wai-Yee Wong [16]. Two years is a practical standpoint considering the difficulty controlling patient dropouts over time [35].

Figini [6] reported two randomized controlled trials that both compared radiographic periapical healing after root canal treatment of necrotic teeth completed in one visit or two visits. There were no statistically significant differences in healing between the two groups as in the present study. Several studies have shown that there is a significant relationship between extrusion of debris and postoperative pain under clinical 


\section{Open Access Journal of Neurology \& Neurosurgery}

circumstances. This relationship might indicate the role of other factors, in addition to the extrusion of debris, in the severity of postoperative pain [37]. In this study, we used the EndoVac, a negative pressure irrigation technique developed to avoid those adverse effects even when the needle was placed as far apically as the working length. Nielsen \& Baumgartner [14] showed that there are significant differences in the cleaning effect at the apical $1 \mathrm{~mm}$ level using the EndoVac technique in comparison to a conventional positive pressure technique. In the present study, age had no significant relationship with the rate of endodontic flare-up. Similar findings were also reported by Eleazer PD \& Eleazer KR [34].

\section{Conclusion}

This study gave evidence that a meticulously instrumentation, irrigation and the kinematics adopted during reciprocating instrumentation performed in a single-visit root canal treatment can be as successful as a two-visit treatment. There was no significant difference in radiographic evidence of periapical healing between single-visit and two-visit root canal treatment. Effective pain management revolves around the consideration of a proper diagnosis, dental treatment, and drug therapy. Of course, the diagnosis of a patient's pain must be correct if any therapy is to be successful.

\section{Referances}

1. Morse D, Koren L, Esposito JV,Goldberg JM, Belott RM (1986) Asymptomatic teeth with necrotic pulps and associated periapical radioluciences relationship of flare-ups to endodontic instrumentation, antibiotic usage and stress in three separate practices at three time periods. Int J Psychosom 33(1): 5-87.

2. Walton R, Fouad A (1992) Endodontic interappointment flare-ups: a prospective study of incidence and related factors. J Endod 18(4): 172177.

3. (2015) Glossary of Endodontic Terms. American Association of Endodontic, USA, pp. 1-52.

4. Siqueira JF, Araujo MC, Garcia PF, Fraga RC, Dantas CJ (1997) Histological evaluation of the effectiveness of five instrumentation techniques for cleaning the apical third of root canals. J Endod 23(8): 499-502.

5. Albashaireh Z, Alnegrish AS (1998) Postobturation pain after single and multiple visit endodontic therapy. A prospective study. J Dent 26(3): 227-232.

6. Figini L, Lodi G, Gorni F, Gagliani M (2008) Single versus Multiple Visits for Endodontic Treatment of Permanent Teeth: A Cochrane Systematic Review. J Endod 34(9): 1041-1047.

7. Soares JA, César CAS (2001) Clinic and radiographic evaluation of one-appointment root canal therapy in teeth with chronic periapical lesions. Pesqui Odontol Bras 15(2): 138-144.

8. Kakehashi S, Stanley HR, Fitzgerald RJ (1965) The effects of surgical exposures of dental pulps in germfree and conventional laboratory rats. Oral Surg Oral Med Oral Pathol 20(3): 340-349.

9. Möller AJ, Fabricius L, Dahlén G, Ohman AE, Heyden G (1981) Influence on periapical tissues of indigenous oral bacteria and necrotic pulp tissue in monkeys. Scan J Dent Res 89(6): 475-484.

10. Siqueira JF Jr (2001) Strategies to treat infected root canals. J Calif Dent Assoc 29(12): 825-837.
11. Ng YL, Glennon JP, Setchell DJ, Gulabivala K (2004) Prevalence of and factors affecting post-obturation pain in patients undergoing root canal treatment. Int Endod J 37(6): 381-391.

12. Peters LB, Wesselink PR (2002) Periapical healing of endodontically treated teeth in one and two visits obturated in the presence or absence of detectable microorganisms. Int Endod J 35(8): 660-667.

13. Byström A, Sundqvist G (1981) Bacteriologic evaluation of the efficacy of mechanical root canal instrumentation in endodontic therapy. Scan J Dent Res 89(4): 321-328.

14. Nielsen BA, Craig Baumgartner J (2007) Comparison of the Endo-Vac system to needle irrigation of root canals. J Endod 33(5): 611-615.

15. Roane JB, Dryden JA, Grimes EW (1983) Incidence of postoperative pain after single- and multiple-visit endodontic procedures. Oral Surg Oral Med Oral Pathol 55(1): 68-72.

16. Wong AW, Tsang CS, Zhang S, Li KY, Zhang C, et al. (2015) Treatment outcomes of single-visit versus multiple-visit non-surgical endodontic therapy: a randomized clinical trial. BMC Oral Health 15: 162.

17. Ashkenaz PJ (1979) One-visit endodontics: a preliminary report. Dent Surv 55(1): 62-67.

18. www.cirp.org/library/ethics/helsinki

19. Pocock SJ (1983) Clinical Trials. A Practical Approach, John Wiley \& Sons, UK, pp.1-278.

20. Walters SJ (2004) Sample size and power estimation for studies with health related quality of life outcomes: a comparison of four methods using the SF-36. Health Qual Life Outcomes 25(2): 26.

21. Ørstavik D, Pitt Ford TR (1998) Essential endodontology: prevention and treatment of apical periodontitis. $\left(2^{\text {nd }} \mathrm{edn}\right)$, Wiley-Blackwell price, UK, pp. 448.

22. Strindberg LZ (1956) The dependence of the results of pulp therapy on certain factors. Acta Odontol Scand 14 (supplement 21).

23. Mattscheck DJ, Law AS, Noblett WC (2001) Retreatment versus initial root canal treatment: factors affecting post treatment pain. Oral Surg Oral Med Oral Pathol Oral Radiol Endod 92(3): 321-324.

24. Glennon JP, Ng YL, Setchell DJ, Gulabivala K (2004) Prevalence of and factors affecting post preparation pain in patients undergoing twovisit root canal treatment. Int Endod J 37(1): 29-37.

25. Yoldas O, Topuz A, Isci AS, Oztunc H (2004) Postoperative pain after endodontic retreatment: single versus two-visit treatment. Oral Surg Oral Med Oral Pathol Oral Radiol and Endod 98(4): 483-487.

26. Oliet S (1983) Single-visit endodontics: a clinical study. J Endod 9(4): $147-152$.

27. DiRenzo A, Gresla T, Johnson BR, Rogers M, Tucker D, et al. (2002) Postoperative pain after 1-and 2-visit root canal therapy. Oral Surg Oral Pathol Oral Radiol and Endod 93(5): 605-610.

28. Torabinejad M, Kettering JD, McGraw JC, Cummings RR, Dwyer TG, et al. (1988) Factors associated with endodontic interappointment emergencies of teeth with necrotic pulps. Journal of Endodontics 14(5): 261-266.

29. Siqueira JF, Roças IN, Favieri A, Machado AG, Gahyva SM, et al. (2002) Incidence of postoperative pain after intracanal procedures based on an antimicrobial strategy. J Endod 28(6): 457-460.

30. Fava LRG (1991) One-appointment root canal treatment: incidence of postoperative pain using a modified double- flared technique. Int Endod J 24(5): 258-262.

31. Sjögren U, Hagglund B, Sundqvist G, Wing K (1990) Factors affecting the long-term results of endodontic treatment. J Endod 16(10): 498504 . 
32. Sathorn C, Parashos P, Messer HH (2005) Effectiveness of single- versus multiple-visit endodontic treatment of teeth with apical periodontitis: a systematic review and meta-analysis. Int Endod J 38(96): 347-355.

33. Estrela C, Sydney GB, Bammann LL, Felippe Junior O (1995) Mechanism of action of calcium and hydroxyl ions of calcium hydroxide on tissue and bacteria. Braz Dent J 6(2): 85-90.

34. Eleazer PD, Eleazer KR (1998) Flare-up rate in pulpally necrotic molars in one-visit versus two-visit endodontic procedures. J Endod 24(9): 614-616.

This work is licensed under Creative Commons Attribution 4.0 Licens DOI: 10.19080/OAJNN.2017.6.555689
35. Peters LB, Wesselink PR, Moorer WR (1995) The fate and the role of bacteria left in root dentinal tubules. Int Endod J 28(2): 95-99.

36. Weiger R, Rosendahl R, Löst C (2000) Influence of calcium hydroxide intracanal dressings on the prognosis of teeth with endodontically induced periapical lesions. Int Endod J 33(3): 219-226.

37. Pasqualini D, Mollo L, Scotti N, Cantatore G, Castellucci A, et al. (2012) Postoperative pain after manual and mechanical glide path: a randomized clinical trial. J Endod 38(1): 32-36.

\begin{tabular}{|l|}
\hline \multicolumn{1}{|c|}{ Your next submission with Juniper Publishers } \\
will reach you the below assets \\
- Quality Editorial service \\
- Swift Peer Review \\
- Reprints availability \\
- E-prints Service \\
- Manuscript Podcast for convenient understanding \\
- Global attainment for your research \\
- Manuscript accessibility in different formats \\
( Pdf, E-pub, Full Text, Audio) \\
- Unceasing customer service \\
Track the below URL for one-step submission \\
https://juniperpublishers.com/online-submission.php \\
\hline
\end{tabular}

